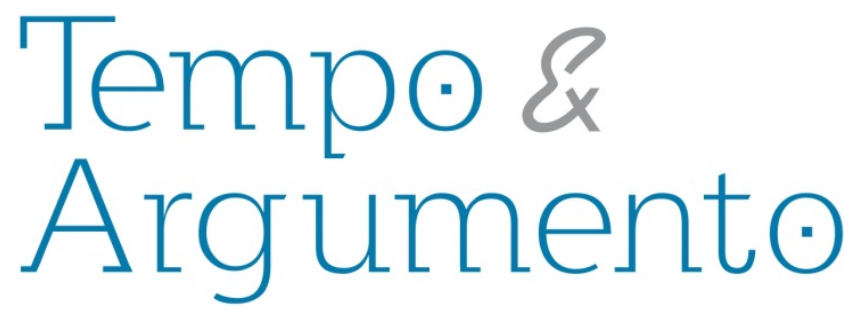

\title{
Clases sociales, ideología y cuestión nacional en el debate entre las FAR y el PRT-ERP en Argentina
}

\begin{abstract}
Resumen
El propósito de este artículo es explorar los principales nudos argumentativos del debate entre las Fuerzas Armadas Revolucionarias (FAR) y el Partido Revolucionario de los Trabajadores-Ejército Revolucionario del Pueblo (PRT-ERP), dos organizaciones armadas argentinas de la década de 1970. La discusión se desarrolló entre abril y noviembre de 1971, y su disparador fue un reportaje a las FAR publicado en la revista Cristianismo y Revolución. A este documento le siguió "Responde el ERP”, una breve réplica de presos políticos, y a continuación la respuesta de las FAR con sus "Aportes al proceso de confrontación de posiciones y polémica pública que abordamos con el ERP”. En este trabajo indagamos puntualmente el papel atribuido en el debate a las clases sociales, para profundizar su relación con otros tópicos, como la cuestión nacional y la ideología. Nos interesa estudiar el significado de estas categorías desde el punto de vista de los actores históricos, para rastrear en que constelación ideológica y discursiva se ubican.
\end{abstract}

Palabras clave: Clase Social; Ideología; Cuestión Nacional; Guerrilla Argentina.

\author{
Esteban Campos \\ Profesor de Historia de América III \\ (independiente) en la Universidad de Buenos \\ Aires. Investigador asistente del CONICET. \\ Miembro del Grupo de Trabajo CLACSO \\ "Violencia y política. Un análisis cultural de las \\ militancias de izquierda en América Latina". \\ Argentina. \\ estebancampos1977@gmail.com
}

Para citar este artículo:
CAMPOS, Esteban. Clases sociales, ideología y cuestión nacional en el debate entre las FAR y el
PRT-ERP en Argentina. Tempo e Argumento, Florianópolis, v. 7, n.16, p. 183 - 204. set./dez. 2015.

DOI: $\mathbf{1 0 . 5 9 6 5 / 2 1 7 5 1 8 0 3 0 7 1 6 2 0 1 5 1 8 3}$

http://dx.doi.org/10.5965/21751803071652015183 


\section{Social classes, ideology, and national issue in the debate between the FAR and the PRT-ERP}

\section{Classes sociais, ideologia e questão nacional no debate entre as FAR e o PRT-ERP na Argentina}

\begin{abstract}
The purpose of this paper is addressing the main argumentative cores in the debate between the Fuerzas Armadas Revolucionarias (FAR) and the Partido Revolucionario de los Trabajadores-Ejército Revolucionario del Pueblo (PRT-ERP), two armed organizations in the 1970s. The discussion took place between April and November 1971 and its trigger was a report on the FAR published by the serial Cristianismo y Revolución. This document was followed by "Responde el ERP," a brief replica prepared by political prisoners, and then the response by the FAR with its "Aportes al proceso de confrontación de posiciones y polémica pública que abordamos con el ERP." In this paper, we address in detail the role assigned in the debate to social classes, to deepen its relation with other topics, such as the national issue and ideology. We are interested in studying the meaning of these categories from the viewpoint of historical players, to track which ideological and discursive constellation they are in.
\end{abstract}

Keywords: Social Class; Ideology; National Issue; Argentine Guerrilla.

\begin{abstract}
Resumo
O propósito deste artigo é explorar os principais nós argumentativos do debate entre as Forças Armadas Revolucionárias (FAR) e o Partido Revolucionário dos Trabalhadores-Exército Revolucionário do Povo (PRTERP), duas organizações armadas argentinas dos anos 1970. A discussão ocorreu entre abril e novembro de 1971 e seu gatilho foi uma reportagem sobre as FAR publicada na revista Cristianismo y Revolución. Esse documento foi seguido por "Responde o ERP", uma breve réplica de prisioneiros políticos, e, em seguida, a resposta das FAR, com seus "Aportes al proceso de confrontación de posiciones y polémica pública que abordamos con el ERP" [Contribuições ao processo de confronto de posições e controvérsia pública que abordamos com o ERP]. Neste trabalho, investigamos pontualmente o papel atribuído no debate às classes sociais, para aprofundar sua relação com outros tópicos, como a questão nacional e a ideologia. Buscamos estudar o significado dessas categorias sob o ponto de vista dos atores históricos, para investigar em qual constelação ideológica e discursiva estão localizadas.
\end{abstract}

Palavras-chave: Classe Social; Ideologia; Questão Nacional; Guerrilha Argentina.

En la discusión científica, puesto que se supone que el interés es la búsqueda de la verdad y el progreso de la ciencia, resulta más "avanzado" el que se sitúa en el punto de vista de que el adversario puede estar expresando una exigencia que hay que incorporar, aunque sea como momento subordinado, a la construcción propia. 
El propósito de este artículo es explorar los principales nudos argumentativos del debate entre las Fuerzas Armadas Revolucionarias (FAR) y el Partido Revolucionario de los Trabajadores-Ejército Revolucionario del Pueblo (PRT-ERP), dos organizaciones político-militares que operaron en la Argentina de la década de 1970. La discusión se desarrolló entre abril y noviembre de 1971, y su disparador fue la publicación de un extenso reportaje a las FAR en la revista Cristianismo y Revolución. ${ }^{1}$ En la entrevista, el grupo armado liderado por Carlos Olmedo expuso una serie de polémicas afirmaciones en torno al significado del peronismo, el marxismo, la vanguardia y la lucha armada. La respuesta al controvertido documento no se hizo esperar: entre abril y mayo de 1971, un grupo de presos políticos del ERP, recluidos en la Cárcel de Encausados de Córdoba, dio a conocer un breve folleto titulado "Responde el ERP", donde se criticaron varios puntos de la presentación de las FAR. El asesinato de Olmedo en la provincia de Córdoba durante el "Combate de Ferreyra", el 3 de noviembre de 1971, impidió la redacción final de una amplia réplica que el dirigente de las FAR venía preparando. Sin embargo, sus compañeros publicaron el borrador junto a la primera y única respuesta del ERP en un nuevo documento, llamado "Aportes al proceso de confrontación de posiciones y polémica pública que abordamos con el ERP" (BASCHETTI, 2004, p.186-214). La muerte de Olmedo interrumpió oficialmente el debate, pero la polémica continuó en las cárceles que alojaban a los presos políticos de ambos grupos armados, como el penal de Rawson o la cárcel de Villa Devoto.

Si es posible considerar este duelo discursivo como uno de los puntos más altos del intercambio político, ideológico y cultural al interior de la guerrilla argentina, nos interesa desmontar los ejes centrales del debate, como el peronismo, la vanguardia, el nacionalismo, el internacionalismo y el marxismo. Por eso, vamos a estudiar el significado de estas categorías desde el punto de vista de los actores históricos, así como rastrear en que constelación ideológica y discursiva se ubican, a que prácticas y lecturas se remiten.

\footnotetext{
“Los de Garín”, Cristianismo y Revolución, 28, 56-70, abril de 1971. Disponible en: <http://eltopoblindado.com/revista-cristianismo-y-revolucion/>. Cristianismo y Revolución fue una revista publicada entre 1966 y 1971 en Argentina por el ex seminarista Juan García Elorrio y un grupo de militantes que provenían de las juventudes católicas radicalizadas por el Concilio Vaticano II y las revoluciones del Tercer Mundo. Fue un espacio de cruce entre el cristianismo liberacionista, la izquierda peronista y las organizaciones armadas.
} 
En este artículo, vamos a indagar puntualmente el papel atribuido en el debate a las clases sociales, para profundizar su relación con otros tópicos de la polémica, como la cuestión nacional y la ideología. A fines de los años sesenta, el régimen militar encabezado por Juan Carlos Onganía empezó a mostrar sus primeros signos de agotamiento, acosado por una ola de protestas que se había extendido rápidamente entre los trabajadores y las capas medias. Si 1969 había sido el año de la espectacular insurrección obrera y estudiantil del Cordobazo, 1970 fue el momento de la guerrilla urbana en Argentina (ANZORENA, 1998, p.93). ${ }^{2}$ El surgimiento de organizaciones políticomilitares como el PRT-ERP, las FAR y Montoneros se sumó al accionar de los grupos guerrilleros preexistentes, como las Fuerzas Armadas Peronistas (FAP), el comando Descamisados y las Fuerzas Argentinas de Liberación (FAL). La multiplicación de las guerrillas urbanas en todo el país acabó con el monopolio de la violencia que detentaba la dictadura militar y contribuyó a erosionar su poder. Las insurrecciones populares que habían sacudido a las provincias de Corrientes, Córdoba y Rosario entre mayo y septiembre de 1969 mostraron la magnitud del descontento social en proporciones nunca vistas, cuyo emergente más visible fue el intenso proceso de radicalización obrera y estudiantil. El gobierno de Onganía continuó su marcha a los tropezones, pero terminó de derrumbarse el 29 de mayo de 1970, con el secuestro de Pedro Eugenio Aramburu, protagonista posible de una salida electoral. Tan solo diez días después de su desaparición, la Junta de Comandantes le pidió la renuncia al presidente de facto y lo reemplazó por Roberto Marcelo Levingston, que en este momento se encontraba en Estados Unidos como agregado militar. A pesar de la rotación de los militares en el gobierno y la promesa de un cambio con el nombramiento del desarrollista Aldo Ferrer al frente del Ministerio de Economía, la situación política se complicaba cada vez más, conforme aumentaban el accionar de las organizaciones político-militares y crecía el estado de insurgencia civil. En marzo de 1971, Córdoba volvió a ser el epicentro de la

\footnotetext{
${ }^{2}$ En la década de 1960, se realizaron varias acciones de guerrilla urbana en el país, pero ninguna logró desestabilizar el escenario político: los últimos comandos de la Resistencia peronista, el asalto al Policlínico Bancario de la ciudad de Buenos Aires por parte del Movimiento Nacionalista Revolucionario Tacuara (MNRT), el robo de armamento en un cuartel militar por las Fuerzas Argentinas de Liberación (FAL) en 1969, y varios robos y desarmes de la Guerrilla del Ejército Libertador (GEL). Por otro lado, dos guerrillas fueron desarticuladas en áreas rurales antes de que entren en acción: el Ejército Guerrillero del Pueblo (1963-1964) y las Fuerzas Armadas Peronistas (1968).
} 
protesta contra la dictadura, cuando la CGT local declaró una huelga con movilizaciones en contra del nuevo interventor Camilo Uriburu. Este nuevo episodio de lucha en las calles, conocido popularmente como el Viborazo, provocó la renuncia de Levingston y su delegado en Córdoba. El 26 de marzo, asumió como presidente el Comandante en Jefe de las Fuerzas Armadas, Alejandro Agustín Lanusse.

\section{Las FAR y el PRT-ERP, de cara al debate}

Las FAR surgieron de la fusión de varios grupos, como el de Arturo Lewinger y su Tercer Movimiento Histórico, o de disidentes del Partido Comunista Argentino, como Carlos Olmedo, Roberto Quieto y Marcos Osatinsky. En el caso de Arturo Lewinger, el Tercer Movimiento Histórico fue una escisión nacional-popular del Movimiento de Izquierda Revolucionaria-Praxis, organización político-cultural conducida por Silvio Frondizi. El Tercer Movimiento Histórico apostaba a un bonapartismo modernizador, en la idea de que un golpe militar nacionalista iba a desencadenar una transformación revolucionaria de la estructura atrasada del capitalismo argentino (CAVIASCA, 2006, p.8297). Los grupos que venían del Partido Comunista habían protagonizado dos rupturas: la primera fue la de Vanguardia Revolucionaria, en 1963, donde militaban Roberto Quieto y Elisa Pastoriza. El grupo liderado por Carlos Olmedo, vinculado a la revista La Rosa Blindada, se separó del Partido Comunista en $1965 .{ }^{3}$ Otras agrupaciones que se sumaron a las FAR fueron los Comandos Santiago Pampillón, dirigidos por Julio Roqué, algunos militantes de la Democracia Cristiana con presencia en el noroeste de Argentina, y combatientes de la Guerrilla del Ejército Libertador (GEL), provenientes de Santiago del Estero y La Plata. El denominador común en la unificación de todos estos grupos fue la formación de células de apoyo a la guerrilla de Ernesto Guevara en Bolivia, que empezaron a organizarse a fines de 1966. Sin embargo, la propia muerte del Che en Ñancahuazú detuvo abruptamente esta iniciativa y contribuyó a desatar un rápido

\footnotetext{
${ }^{3}$ Las disidencias del PC se producen por varios motivos, entre ellos las críticas internas al rol opositor del partido en el primer peronismo, su posición frente a los procesos de lucha armada en el Tercer Mundo y el apoyo a la Unión Soviética en su enfrentamiento con la China comunista. Otra ruptura importante fue la de los miembros de Pasado y Presente, revista publicada por ex militantes comunistas, como Oscar del Barco y José María Aricó, entre 1963 y 1965, o la separación de un nutrido sector de la Federación Juvenil Comunista, que hacia 1968 fundó el Partido Comunista Revolucionario.
} 
proceso de nacionalización de la guerrilla guevarista, que modificó su perspectiva continental de la lucha armada. El giro hacia lo nacional permitió una nueva apreciación del peronismo como movimiento popular, sin abandonar la teoría del foco en su argumento central. La estrategia de derrotar el ejército burgués mediante una serie progresiva de hechos armados que galvanizaran la movilización de las masas permaneció intacta, pero la idea de llevar las acciones armadas a las grandes ciudades también cambió el sujeto revolucionario. La clase obrera fue vista como el detonante a ser activado por el foco guerrillero, y el movimiento peronista se convirtió en el vehículo para iniciar un proceso revolucionario de liberación nacional, capaz de avanzar hacia una sociedad socialista. De esta manera, las FAR asumieron el peronismo como identidad política sin disimular que sus orígenes se remontaban a la izquierda marxista.

El 26 de junio de 1969, estallaron bombas prolijamente ocultas dentro de pomos de dentífrico en trece supermercados Minimax, una novedad del capital extranjero que estaba arruinando a los almacenes de la pequeña burguesía. El atentado fue realizado para darle la bienvenida a Nelson Rockefeller en su gira latinoamericana ${ }^{4}$, y fue el primer operativo de envergadura realizado por varios de los comandos que más tarde formarían las FAR. Un año más tarde, la organización inició una febril actividad que los llevó a crear regionales en Buenos Aires, La Plata, Tucumán y Córdoba (CANOSA, 2012, p.136-137). El 30 de julio de 1970, un comando de las FAR tomó la localidad de Garín, en la provincia de Buenos Aires, y se dio a conocer en público a través de un comunicado. La audacia demostrada en esta acción y las operaciones que le sucedieron permitió que las FAR se ubiquen entre las principales organizaciones político-militares del momento, pero al mismo tiempo llamó la atención de las fuerzas represivas. El 2 de julio de 1971, dos integrantes de las FAR, Marcelo Verd y Sara Palacios, cayeron secuestrados en la provincia de San Juan y fueron sometidos a tortura, para revelar el paradero de sus compañeros. Once días después, Juan Pablo Maestre y Mirta Misetich fueron asesinados tras ser raptados por un grupo parapolicial. Las FAR sufrían así sus primeras bajas, y

\footnotetext{
${ }^{4}$ Nelson Rockefeller (1908-1979) fue un político estadounidense del Partido Republicano, miembro de una poderosa familia de políticos y empresarios, que ganó poder y fortuna gracias a la empresa Standard Oil. En 1969, mientras se desempeñaba como gobernador de Nueva York, recibió la invitación para visitar América Latina, tarea que Rockefeller convirtió una Misión Presidencial que recorrió veinte países de la región, y fue célebre por las protestas que generó en todos ellos (MORGENFELD, 2013, p.93).
} 
comenzaban un proceso de acercamiento con varias organizaciones guerrilleras. El 10 de abril de 1972, un operativo conjunto con el ERP acabó con la vida del Teniente General Juan Carlos Sánchez, pero lo más significativo ocurrió el 12 de octubre de 1973, con la declaración formal de la fusión entre las FAR y los Montoneros.

Los inicios del PRT-ERP se remontan al Partido Revolucionario de los Trabajadores, fundado en 1965. Se trataba de una organización política que se formó gracias a la unificación de dos grupos: Palabra Obrera, dirigido por Nahuel Moreno, y el Frente Revolucionario Indoamericanista Popular (FRIP), liderado por Mario Roberto Santucho. Mientras el trotskista Palabra Obrera tenía presencia en los principales centros urbanos de Argentina y había cosechado vínculos con la resistencia peronista, el FRIP era una organización más pequeña influenciada por el aprismo peruano y la revolución cubana, con un trabajo político desarrollado en las universidades y los ingenios azucareros del noroeste. Tras definir su identidad trotskista, en los primeros años de vida del PRT se multiplicaron los debates internos, especialmente en torno a la posibilidad de iniciar un proceso de lucha armada en Argentina. Los dirigentes otrora ligados a Palabra Obrera sostenían que las condiciones objetivas para tal enfrentamiento no estaban dadas, pero los que tenían un pasado en el FRIP apoyaban con entusiasmo la opción por las armas, afirmando que el partido debía organizar sus propias unidades de combate (POZZI, 2004, p.23-24). En 1968, el PRT se fracturó a causa de estas discusiones y se formaron dos agrupaciones separadas: La verdad, conducida por Nahuel Moreno, y El combatiente, dirigida por Mario Roberto Santucho. En el IV Congreso del PRT, organizado en marzo del mismo año por la fracción proclive a la lucha armada, se criticaron las posiciones "reformistas" de Moreno y se dieron pasos decisivos en dirección a la construcción de una nueva identidad política, como se puede advertir en su documento oficial, El único camino al poder obrero y el socialismo. Allí, Mario Roberto Santucho, junto a Oscar Prada y Félix Helio Prieto, dos antiguos cuadros de Palabra Obrera, realizaron una apretada y ecléctica síntesis política, que trató de combinar los aportes de Marx, Engels, Lenin, el trotskismo, el maoísmo y el castrismo (SANTUCHO, 2006, p.15-37). ${ }^{5}$

\footnotetext{
${ }^{5}$ En esta síntesis no aparece reflejada la gran deuda que ha tenido el PRT-ERP con la tradición revolucionaria vietnamita, a través de los escritos de Vo Nguyen Giap y Ho-Chi-Minh.
} 
En 1969, el PRT El combatiente inició sus primeras acciones armadas, con una serie de pruebas y errores que incluyeron la captura de varios militantes de la organización en Tucumán. Por esta razón, fue recién en el V Congreso del PRT, realizado en julio de 1970, cuando se caracterizó a la situación nacional como una guerra revolucionaria y se creó el Ejército Revolucionario de Pueblo, en medio de una dura lucha de fracciones internas por el poder de la joven organización. A partir del V Congreso, el ERP se organizó como un brazo armado con un programa antiimperialista y popular, a diferencia del PRT, que se reivindicaba socialista y clasista. La relación entre estas dos entidades no siempre fue transparente: aunque la depuración de tendencias concentró el liderazgo en Santucho, formalmente el PRT-ERP se estructuró desde este momento como un partido marxista de combate, con un buró político y un comité militar. Este diseño organizativo sirvió para diferenciarlos nítidamente de la típica organización político-militar con comandancia unificada, modelo predominante entre las guerrillas marxistas y peronistas de los 1970. Por otro lado, en un principio, la gran mayoría de los combatientes del ERP eran al mismo tiempo militantes del PRT, aunque para revistar en los comandos, las escuadras y los pelotones no era requisito indispensable afiliarse al partido (POZZI, 2004, p.97-102, p.243249). Desde 1970, el ERP experimentó un crecimiento sostenido y una fuerte exposición mediática, que no desmereció pero sin duda eclipsó el accionar del PRT en los frentes de masas. En septiembre de 1970, el ERP hizo su primera aparición pública tomando la comisaría 24 de Rosario, enfrentamiento que culminó con dos policías muertos y varios heridos. En la primera mitad de 1971, en vísperas del debate con las FAR, el ERP se destacó como la organización político-militar que más operaciones guerrilleras había realizado en el país, si bien en conjunto los grupos armados peronistas fueron los protagonistas de la mayoría de las acciones. Entre marzo y julio de ese año se realizaron 316 operativos, de los cuales 120 fueron firmados por el ERP, 26 por las FAL, 16 por Montoneros, 4 por las FAP y 137 acciones, casi la mitad, eran responsabilidad de organizaciones peronistas o de grupos innominados (ANZORENA, 1998, p.121).

En el número 28 de Cristianismo y Revolución, correspondiente a abril de 1971, se publicó un dossier titulado Reportaje a la guerrilla argentina, con testimonios de las FAR, FAP, Montoneros y FAL. A la cabeza de la sección, se incluyó una entrevista de Paco 
Urondo a Carlos Olmedo, que debido a razones de seguridad y por tratarse de una declaración oficial de la organización no develaron su identidad (DUHALDE y PÉREZ, 2003, p.66). Según el copete que introducía al lector en las circunstancias que rodearon la producción del texto, la serie de reportajes fue publicada originalmente en el diario cubano Granma hacia diciembre de 1970, aunque más tarde "una agencia noticiosa recogió el extenso reportaje que reproducimos en primer lugar", refiriéndose a la revista chilena Punto Final. Si para Cristianismo y Revolución las FAR “explican allí su acercamiento al peronismo anticipando una futura decisión política al respecto”, en esta versión de la entrevista Olmedo no incluye a su organización dentro del movimiento peronista. Sin embargo, cinco meses después, en la entrevista que reproduce Cristianismo y Revolución, aparece una clara identificación con el peronismo. La confusa introducción del reportaje a la guerrilla argentina contribuyó a oscurecer estas modificaciones, y hasta el día de hoy en varias investigaciones se repite el error de creer que la entrevista de abril de 1971 es la misma que aquella publicada en el Granma. ${ }^{6}$ Vamos a analizar de aquí en adelante como se relacionan los tópicos de clase social, nación e ideología en el debate entre las FAR y el PRT-ERP.

\section{Clase y nación}

Aunque el problema de la cuestión nacional en las izquierdas se había desarrollado en las primeras décadas del siglo XX a partir de la crítica del imperialismo, en Argentina fue ante todo el primer peronismo y su caída quien abrió una brecha en la militancia revolucionaria. A las revistas como Pasado y Presente o Contorno, que interpelaron el tópico de la cuestión nacional mediante una puesta en valor del peronismo, se sumaron los intentos de un sector del trotskismo para insertarse en la rama sindical del

\footnotetext{
${ }^{6}$ Mora González Canosa (2012: p.145) demuestra que existe una confusión en torno a la entrevista del Granma, observa que esta fue realizada en vistas a su publicación en Cristianismo y Revolución: "Producto de la confusa introducción de la revista al documento, suele citarse el reportaje a las FAR 'Los de Garín', publicado en Cristianismo y Revolución, en donde por primera vez la organización se declara públicamente como peronista, como aquél que habría sido publicado en el diario cubano 'Gramma', en diciembre de 1970. En realidad, ese reportaje fue realizado entre febrero y marzo de 1971, siendo publicado inmediatamente en CyR. El reportaje que verdaderamente se publicó en el 'Gramma' fue 'FAR: Con el fusil del Che', en el cual la organización valoriza positivamente el rol del peronismo pero no se incluye como parte del movimiento".
} 
movimiento, sin liquidar su identificación original con las izquierdas (ALTAMIRANO, 2001). En el reportaje publicado por Cristianismo y Revolución, las clases sociales hacen su primera aparición desde el inicio, cuando Carlos Olmedo remarca el vínculo primigenio entre las FAR y la guerrilla del Che en Bolivia:

Y es significativo señalar que la unidad de análisis que estamos usando es América Latina, porque en alguna medida el propio proyecto estratégico que nos mueve tiene todavía muy poco en cuenta la formación social específica llamada Argentina, y en cambio se maneja con categorías más abarcadoras -pero por lo mismo bastante abstractas- como América Latina, Tercer Mundo, etc. Esto, que podría ser un encuadre correcto en el proyecto estratégico del Che, asumido sin mediaciones por nosotros, nos convertía en una pequeña patrulla extraviada en el espacio de la lucha de clases... ${ }^{7}$

Es interesante este pasaje, porque la mención a la lucha de clases se introduce para explicar el tránsito de la revolución continental promovida por el Che Guevara desde su llegada a Bolivia, en 1966, a una acción circunscripta al territorio nacional. Desde este punto de vista, las clases sociales eran fuerzas sociales que se definían por su posición en el proceso de producción, pero también por su experiencia de lucha dentro de los límites del Estado burgués. ${ }^{8}$ En consecuencia, para Olmedo, el sujeto revolucionario era la clase obrera peronista, un argumento que coloniza el relato y margina del análisis a otros elementos de la formación social, como las distintas capas de la burguesía. Este recorte generaba un potente efecto de sentido: si la clase obrera era peronista, entonces el peronismo era fundamentalmente una experiencia obrera, y aquellos peronistas que por su extracción de clase o posición política se alineaban con los intereses burgueses no hacían más que traicionar su esencia.

Si las FAR diseñaron su estrategia a partir de un análisis de la historia nacional que los condujo a una valorización del fenómeno peronista, el ERP, por el contrario, emplearía en su documento de respuesta una grilla conceptual que procedía de manera opuesta:

\footnotetext{
7 “Los de Garín", Cristianismo y Revolución, 28, 56, abril de 1971. Disponible en: <http://eltopoblindado.com/files/Publicaciones/Publicaciones\%20Afines/Cristianismo\%20y\%20Revoluci\%C3 \%B3n/Cristianismo\%20y\%20Revoluci\%C3\%B3n\%20N\%C2\%BA\%2028.pdf>.

${ }^{8}$ Cristianismo y Revolución, op. cit., 57.
} 
En primer lugar, debemos hacer un análisis de la situación económica capitalista mundial y de la lucha revolucionaria internacional teniendo en cuenta que la revolución socialista es internacional por su contenido y nacional por su forma. Debemos pasar luego a efectuar un análisis de la situación económica y de la lucha revolucionaria en la región y el mundo, tomando en cuenta el desarrollo de las fuerzas productivas que nos permitirá tener un primer criterio para estimar las posibilidades de una verdadera revolución (si el capitalismo aún puede o no desarrollar las fuerzas productivas), la existencia o no de clases revolucionarias, la relación entre la superestructura política y la estructura social, el desarrollo desigual de la economía, las fuerzas revolucionarias país a país, región a región, etc. (BASCHETTI, 2004, p.184-185).

Para la organización dirigida por Mario Roberto Santucho, la expansión del capitalismo mundial obliga a captar la "situación de conjunto", apreciando las contradicciones y las luchas de clases a escala nacional, regional e internacional. El resultado de esta matriz de análisis es la concepción de la clase obrera argentina como parte del movimiento comunista global, que hace las veces de sujeto revolucionario. En su réplica al documento de los presos del ERP, Carlos Olmedo ridiculiza el método que Ileva de lo universal a lo particular:

Resulta que para estudiar la sociedad argentina en su composición y movimiento hay que empezar... por la situación de la economía capitalista mundial y la lucha revolucionaria internacional. Este disparate metodológico, semejante al que cometería un biólogo que para estudiar la célula empezara... por el cuerpo humano, se justifica por la permanente remisión que se hace al carácter universal del proletariado y la lucha de clases, lo que se hallaría sintetizado en las banderas políticas universales del marxismo leninismo (BASCHETTI, 2004, p.204).

Para las FAR, comprender la historia nacional y el papel de la clase obrera a partir del 17 de octubre de 1945, momento en que los peronistas datan el inicio de su movimiento por la manifestación que liberó a Juan Domingo Perón, es una clave de su línea política. No es que las relaciones de fuerza internacionales carezcan de importancia, pero en la práctica operan como un contexto o marco de lo nacional, puesto que "las causas externas obran por medio de las causas internas" (BASCHETTI, 2004, p.205). ${ }^{9}$ Para

\footnotetext{
${ }^{9}$ La idea de que las causas externas operan por medio de las causas internas fue un argumento utilizado por intelectuales de la izquierda peronista, como Rodolfo Puiggrós y Juan José Hernández Arregui (PUIGGRÓS, 1968, p.70, y HERNÁNDEZ ARREGUI, 1973, p.15).
} 
el ERP, en cambio, es imposible aislar a Argentina del conjunto de los pueblos oprimidos que luchan por su liberación, "como si el triunfo o la derrota del pueblo vietnamita no repercutiera sobre nuestra realidad, no debilitara o fortaleciera a nuestro enemigo" (BASCHETTI, 2004, p.183). De hecho, la revolución vietnamita es un ejemplo utilizado tanto por las FAR como por el PRT-ERP para dar cuenta de la relación entre clase y nación. En el reportaje de Cristianismo y Revolución, Carlos Olmedo justifica la cohabitación de diversas clases sociales en el movimiento peronista afirmando que "la revolución vietnamita es policlasista y no por ello deja de ser revolucionaria", ya que "todo proceso de liberación nacional compromete a más de una clase". ${ }^{10}$ Sin embargo, para las FAR esto no significa la coexistencia pacífica entre el capital y el trabajo, ya que su oposición es el motor del proceso de liberación. La respuesta de los militantes del ERP, que concebían a Vietnam como un modelo de guerra revolucionaria, señala una omisión importante en la argumentación de Olmedo:

\begin{abstract}
Están en lo cierto al afirmar que el policlasismo es una palabra ambigua, pero el esfuerzo que hacen para explicar el tipo de policlasismo que es el peronismo, no lo realizan para explicar la revolución vietnamita que califican de policlasista a secas, sin considerar que su policlasismo responde a las condiciones específicas en que se desenvuelve la guerra de liberación nacional y social vietnamita, con un invasor extranjero en su territorio y bajo la hegemonía absoluta de la clase obrera y el campesinado, acaudillados por su partido marxista-leninista (BASCHETTI, 2004, p.183).
\end{abstract}

Resulta paradójico que, tras marcar las diferencias de sus respectivos métodos de análisis, en esta parte del debate ambos procedan de manera inversa: al citar el caso vietnamita, Olmedo no estaba haciendo otra cosa que universalizar la alianza de clases del movimiento peronista, rehuyendo de su carácter singular. La respuesta del ERP, en cambio, valoraba lo específico de la revolución en Vietnam, llamando la atención sobre la importancia de determinar cuál era la clase que dirigía el proceso de emancipación, y el papel del partido armado como vanguardia. En su contestación al documento perretista, Olmedo enfatizó la oposición entre los movimientos de liberación nacional y la "política marxista a nivel mundial" reivindicada por el trotskismo, que "no existe en ningún lado"

\footnotetext{
10 “Los de Garín”, pág. 65.
} 

volvía al peronismo:

\begin{abstract}
Esencialmente policlasista, el Movimiento Peronista se define desde el comienzo por su carácter nacional-popular, antioligárquico y antiimperialista. Cuando decimos policlasista, decimos que en él participaron, siendo sus columnas fundamentales, la burguesía nacional, nacida al amparo de circunstancias y leyes favorables, y la clase trabajadora, surgida como consecuencia del desarrollo capitalista y de su burguesía autóctona (BASCHETTI, 2004, p.200).
\end{abstract}

El producto ideológico de esta alianza de clases fue la doctrina justicialista, que predicaba la conciliación entre trabajadores y empresarios. Con todo, para Olmedo, el justicialismo no era una "ley eterna", ya que la burguesía nacional de los países dependientes "está condenada a la liquidación" (BASCHETTI, 2004, p.201). ¿Cómo se resolvía entonces la tensión entre los conceptos de lucha de clases y conciliación de clases? Siguiendo la argumentación de los Aportes, la respuesta era la superación del justicialismo por el socialismo, ya que "el interés de la clase trabajadora y el interés nacional se expresan hoy a nivel económico en la expropiación de los capitalistas" (BASCHETTI, 2004, p.201).

\title{
Clase e ideología
}

Más allá de las definiciones políticas, va a ser en el plano de la ideología y la caracterización del marxismo donde se concentre el fuego del debate. A partir de la pregunta por la definición política de su organización, Carlos Olmedo ensayó una argumentación donde las FAR asumieron el peronismo como identidad, la guerra del pueblo como método y la sociedad socialista como fin. Ante la pregunta de si se trataba del socialismo desarrollado en las obras de Marx y Lenin, y cómo se vinculaba la ideología peronista con los aportes del marxismo-leninismo, Carlos Olmedo realizó una extensa digresión sobre el concepto de ideología: 
Quisiera decirle que el concepto de ideología ha llevado y lleva a numerosos equívocos. Sin necesidad de hacer consideraciones académicas, le propongo que al hablar de ideología nos refiramos fundamentalmente a la conciencia que los hombres van logrando de su propia situación. Esa conciencia puede ser clara, penetrante, lúcida, o puede ser incompleta, parcial, distorsionada. El enemigo hace todo lo posible para que esto sea lo que ocurra con la ideología de nuestro pueblo y con nuestra propia ideología. ${ }^{11}$

La ideología aparece aquí como una forma de conciencia capaz de aprehender la totalidad social, pero también como una visión falsa de la realidad, "el conjunto de concepciones que los hombres se forman sobre sí mismos y sobre sus relaciones con los demás" (BASCHETTI, 2004, p.190). Ahora bien, ¿cuál es la relación entre ideología y clase social? Un primer indicio aparece en el relato de la toma de Garín, cuando se trata de explicar el asesinato del cabo Sulling durante el atraco a un banco:

Sulling se resistió absurdamente y nos vimos obligados a disparar sobre él. Esto se ha repetido docenas de veces en combates nuestros y de otras organizaciones armadas [...] Pensamos que una vez más es preciso insistir, no hablando ya para el enemigo, sino para los asalariados que se juegan la vida por intereses que no son de ellos. Para ellos repetimos que las FAR ni ninguna organización revolucionaria tiene interés en liquidarlos. Es al sistema al que hay que liquidar y no a sus representantes más empobrecidos y más golpeados [...] Pienso que este es quizás el problema más importante que hemos ido viendo durante este período. La necesidad de eliminar hombres que desde el punto de vista de su ubicación en el proceso de producción son también trabajadores. ${ }^{12}$

Cuando Olmedo sostenía que la muerte del cabo Sulling era un problema, no se estaba refiriendo solamente a un dilema ético, sino al hecho de que la conducta de ciertos trabajadores no se correspondía con las tareas revolucionarias que les asignaba la teoría. Dicho en otras palabras, no había una relación mecánica entre clase social e ideología, ya que existían "asalariados que se juegan la vida por intereses que no son los de ellos". ${ }^{13}$ En la respuesta del ERP, en cambio, los presos de la cárcel de Córdoba desarrollaron una percepción distinta sobre el mismo tema:

\footnotetext{
12 “Los de Garín”, pág. 62.

12 “Los de Garín”, pág. 60.

13 “Los de Garín”, pág. 60.
} 


\begin{abstract}
Veamos que nos dice Lenin de la ideología en su libro “QQué hacer?”: “Ya que no puede hablarse de una ideología independiente elaborada por las masas obreras en el curso de su movimiento, el problema se plantea así: ideología burguesa o ideología socialista. No hay término medio (pues la humanidad no ha elaborado ninguna tercera ideología, además, en general, en la sociedad desgarrada por las contradicciones de clase nunca puede existir una ideología al margen de las clases ni por encima de las clases). Por eso, todo lo que sea rebajar la ideología socialista, todo lo que sea alejarse de ella, equivale a fortalecer la ideología burguesa". No existiendo una tercera ideología porque científicamente no puede responder a ninguna clase, tan sólo puede ser una variante de la burguesa, deformada y deformante, que se viste con ropajes clasistas y revolucionarios cuando en realidad está expresando un populismo como el peronismo en nuestra realidad histórica (BASCHETTI, 2004, p.181).
\end{abstract}

En este pasaje, la relación entre ideología y clase es transparente, y se confirma mediante una cita de autoridad. El ERP, al igual que las FAR, creía que el proletariado era una fuerza revolucionaria per se, pero llegaba a una conclusión diametralmente opuesta sobre el carácter obrero del peronismo, ya que "no se puede ser marxista y capitalista", pero si "peronista y capitalista como Jorge Antonio" (BASCHETTI, 2004, p.181). ${ }^{14}$ La ideología aparecía aquí con una connotación positiva, como un sistema de valores que reflejaba una determinada estructura de clases. Esto no significaba, empero, la realización de un mecanicismo ideal o absoluto, ya que para ambas organizaciones, la vanguardia era el agente que conducía el proceso revolucionario, y la responsable de divulgar del marxismo entre las clases subalternas. ¿Cómo reaccionaron las FAR frente al planteo del ERP? La respuesta de Olmedo relativizaba la posibilidad de que la clase obrera sea capaz de elaborar una ideología independiente de la burguesía, citando el conocido pasaje de La ideología alemana, según el cual "las ideas de la clase dominante son las ideas dominantes en cada época" (BASCHETTI, 2004, p.190). En consecuencia, el documento resaltaba que los creadores del socialismo científico no eran en modo alguno de origen proletario:

Pero no termina ahí la tarea de la burguesía, que no sólo crea al proletariado de carne y hueso, sino que por intermedio de algunos de sus miembros, intelectuales burgueses, crea también el socialismo científico, la ideología genérica del proletariado. La burguesía no otorga solamente existencia concreta al antagonismo capital-trabajo, sino que crea la conciencia de este antagonismo, conciencia que es adquirida precisamente por algunos de sus miembros en primera instancia (BASCHETTI, 2004, p.190).

\footnotetext{
${ }^{14}$ Jorge Antonio (1917-2007) fue un empresario y político argentino cercano a Juan Domingo Perón.
} 
Desde este punto de vista, dado que Marx y Engels eran burgueses, y como la mayor parte de los trabajadores estaban sometidos a la ideología burguesa, era imposible compartir las tesis del ERP, que "asimilan mecánicamente la extracción de clase con la ideología" (BASCHETTI, 2004, p.192). Para Olmedo, los presos de Córdoba confundían la burocracia con la identidad de clase, olvidando que también se podía ser obrero y peronista. En esta dirección, el comportamiento político se definía por los intereses que se defendían, no por la posición en la estructura social. No obstante las sutilezas teóricas esgrimidas por Carlos Olmedo para sostener sus argumentos, las advertencias del ERP sobre el movimiento liderado por Juan Domingo Perón parecen premonitorias:

[...] no es el peronismo el más adecuado para acaudillar a la clase desposeída, desde el momento que se está buscando la vuelta de su líder para que calme los ímpetus revolucionarios de las masas (BASCHETTI, 2004, p.183).

\section{Consideraciones finales}

[...] en el mismo proletariado, particularmente en el proletariado de las naciones oprimidas, las ideologías nacionalistas siguen vigentes. Y la receptividad de ese proletariado al verdadero internacionalismo no puede ser despertada mediante una anticipación utópica -en el pensamientosobre la situación socialista y el porvenir, donde ya no se suscitarían cuestiones de nacionalidades.

György Lukács

El debate entre las FAR y el PRT-ERP fue un intercambio realizado en condiciones bien singulares. De un lado se encontraba Carlos Olmedo, un cuadro de notables aptitudes políticas e intelectuales, conocido entre los activistas de su organización por diferentes nombres de guerra como José, Germán, Rubio y El exquisito, que era muy respetado por Santucho. Del otro lado se hallaba un grupo de presos políticos liderados por Domingo Menna, un dirigente interesado por la historia del movimiento obrero y el análisis del peronismo, que fueron capaces de producir un escrito en condiciones durísimas de aislamiento, sin tener acceso a libros ni bibliotecas para fundamentar de manera más adecuada sus posiciones teóricas. Aunque discutible, es interesante la impresión que tiene Daniel de Santis sobre los diferentes lenguajes del debate: 
Mi impresión es que aparentemente el estudio de Olmedo tiene más solidez, eso, a mi juicio, es porque Olmedo utilizó como base de la polémica La ideología alemana de Marx y Engels y Menna el Que hacer de Lenin. Filosofía vs. Política. ${ }^{15}$

El reportaje a las FAR, publicado por Cristianismo y Revolución, tuvo dos destinatarios principales: por una parte, los sectores de izquierda más permeables al nacionalismo y la lucha armada, que se intentaba captar a través de una justificación teórica y política de su inserción en el peronismo. Por otra parte, Olmedo trataba de legitimar la nueva identidad de su organización frente al propio movimiento peronista (CANOSA, 2007, p.168-169). Para las FAR, el descubrimiento de la cuestión nacional implicó el pasaje de la estrategia continental del guevarismo a la práctica más localizada de la izquierda peronista, giro que trató de alejar el riesgo de volverse "una patrulla perdida en el espacio de la lucha de clases". La nacionalización de las guerrillas fue una mutación que sufrieron diversos movimientos armados latinoamericanos en la segunda mitad de la década de 1960, tendencia íntimamente ligada a la muerte del Che Guevara en Bolivia y a la derrota de las primeras experiencias de lucha armada inspiradas por el modelo cubano (RODRÍGUEZ OSTRIA, 2005, p.89). El análisis de la formación social a escala nacional y un balance histórico de la experiencia peronista fueron las claves para explicar la formación de la clase obrera argentina. Curiosamente, en el discurso de Carlos Olmedo, la lucha de clases aparecía en contadas ocasiones, ya que en sus extensas digresiones se abandonaba el punto de partida relacional de las clases para referirse únicamente a la clase obrera peronista (acto que impedía pensar al peronismo como una forma de nacionalismo burgués). En este sentido, el carácter policlasista del peronismo aparecía como un eslabón débil de la argumentación, que expresaba la tensión entre el concepto marxista de lucha de clases y la doctrina justicialista de la conciliación de clases.

El documento de los presos políticos del PRT-ERP fue una invitación al debate un tanto atípica, ya que su iniciativa no salió del marco de su dirección. A pesar de todo, como sostiene Abel Bohoslavsky, "para debatir, en el PRT no había que pedirle permiso a nadie. La verticalidad tenía vigencia en tareas, sobre todo militares. Y va de suyo, en la

\footnotetext{
${ }^{15}$ Testimonio de Daniel de Santis, en conversación con el autor (27/08/2013). Los subrayados en negrita le pertenecen al testimoniante.
} 
aplicación de líneas de trabajo previamente adoptadas". 16 La línea política del PRT-ERP aplicaba un método inverso al de las FAR, ya que partía del análisis de la situación internacional y regional para luego volcarse el ámbito local. Por esta razón, lo nacional no ocupaba un lugar central en su concepción política, dado que para esta organización la revolución socialista era internacional por su contenido y nacional por su forma. En esta concepción, la forma era un simple envoltorio del movimiento internacional de las contradicciones que desencadenarían una situación revolucionaria. Desde el punto de vista de la organización dirigida por Mario Roberto Santucho, el peronismo era un movimiento nacionalista burgués, populista y contrarrevolucionario, de allí que el enfrentamiento entre peronistas y antiperonistas sea caracterizado como un puro simulacro. En efecto, para los presos perretistas "la famosa antinomia no existe, lo que existe es una lucha de clases que se da cada vez con mayor intensidad" (BASCHETTI, 2004, p.183). El ERP se esforzó en precisar el significado de conceptos como socialismo y nacionalismo, preocupado por la pureza, la clasificación y la segregación de cada identidad política. Por eso les pareció inconcebible la analogía que ensayó Olmedo entre la revolución vietnamita y el peronismo, ya que en el primer caso se trataba de un país ocupado por una potencia imperialista, con una alianza de clases cuya dirección se apoyaba en un partido armado de ideología marxista-leninista.

Tanto en el PRT-ERP como en las FAR, las ideologías eran expresiones de una determinada estructura de clases. Sin embargo, esta premisa fue llevada a conclusiones opuestas por las dos organizaciones. Para Olmedo, la ideología era ante todo una visión falsa de la realidad producida por las clases dominantes, en sintonía con la caracterización althusseriana de los aparatos ideológicos del Estado (CANOSA, 2007, p.184). Por esta razón, la relación entre clase e ideología era opaca, ya que no había una coincidencia automática entre la clase obrera y sus intereses históricos. En la actitud del cabo Sulling, considerado como un trabajador dispuesto a morir por defender una institución burguesa, aparecía un síntoma del desencuentro entre clase e ideología de clase, ya que en última instancia, como afirmaba Oscar Terán en su lectura de la obra de Régis Debray, "ya no es la ubicación en el modo de producción lo que constituye a los sujetos de clase" (TERÁN, 2004, p.14). Una vuelta de tuerca en la misma línea sería afirmar que, en

\footnotetext{
${ }^{16}$ Testimonio de Abel Bohoslavsky, en conversación con el autor (17/09/2013).
} 
consecuencia, ya no era la línea divisoria entre explotadores y explotados, el lugar en el proceso de producción, lo que definía al ser revolucionario. De hecho, Marx y Engels eran intelectuales burgueses, y como tales tomaron conciencia del antagonismo de clases. Con sus críticas al mecanicismo, Olmedo abrió una puerta, un umbral epistemológico que no quería franquear, porque no tenía la intención de abandonar el marxismo como herramienta de análisis social, incorporado desde su militancia en las filas del Partido Comunista.

Para el PRT-ERP, la ideología era un sistema de valores que reflejaba sin distorsiones una determinada estructura de clases. En esta definición positiva, el marxismo era parte de la ideología proletaria, entendida como una serie de principios basados en el materialismo histórico y dialéctico. Por lo tanto, a diferencia del reportaje de las FAR, donde la ideología aparecía con todas las connotaciones negativas de la falsa conciencia, en la respuesta del ERP, la ciencia se fundió con la ideología, convirtiéndose en un insumo revolucionario. Los presos perretistas se apoyaban en su lectura de Lenin y el ¿Qué hacer? para afirmar que solo existían dos ideologías, la socialista y la burguesa, intrínsecamente ligadas a las dos clases antagónicas del modo de producción capitalista. En este pasaje, la relación entre clase e ideología era transparente y se daba como un mero efecto estructural, ya que no aparecían ni mediaciones (como la del partido de vanguardia) ni distorsiones (como la que significaría el peronismo). Por esta razón, se podía ser peronista y capitalista, o militar y peronista (es decir, ser parte de las clases dominantes y su aparato estatal y adherir al peronismo), pero nunca marxista y capitalista.

¿Qué consecuencias tuvo la polémica al interior de las FAR y el PRT-ERP? Aunque es difícil estudiar la recepción del intercambio en los dos grupos, se podría señalar que las intervenciones de Carlos Olmedo contribuyeron a consolidar la propia identidad de la organización, como muestra la reedición del debate por las FAR tras la muerte de su principal dirigente. En cuanto al PRT-ERP, existen opiniones divididas al respecto: para Daniel de Santis, "nunca se le dio mucha importancia. Los que la han reflotado todo el tiempo son los peronistas revolucionarios". ${ }^{17}$ Sin embargo, el historiador Pablo Pozzi, que realizó numerosas entrevistas a ex militantes de la organización, sostiene que, hasta la

\footnotetext{
${ }^{17}$ Testimonio de Daniel de Santis, en conversación con el autor (27/08/2013).
} 
publicación de la nota en Cristianismo y Revolución, las FAR eran un aliado estratégico de la organización liderada por Santucho. Por lo tanto, el PRT-ERP no solo se habría preocupado por responderle a Olmedo, sino que para Pozzi “el PRT-ERP aceptó la crítica en cuanto a que publicó varios estudios sobre el peronismo que intentaban subsanar el déficit [de formación teórica] sintetizando su posición" (POZZI, 2004, p.107-108). La muerte de Olmedo en el combate de Ferreira hacia 1971, pero quizás también las diferencias cada vez más profundas entre las dos organizaciones a causa del inminente regreso de Perón, impidieron la continuación del debate.

\section{Referências}

\section{Eletrônicas}

“Los de Garín”, Cristianismo y Revolución, varias ediciones. Disponible en: $<$ http://eltopoblindado.com/revista-cristianismo-y-revolucion/>.

MORGENFELD, Leandro. Nelson A. Rockefeller en la Argentina: una visita incómoda tras el Cordobazo, In: Taller, vol. 2 n. 2, 90-103. Disponible en:

<http://www.tallersegundaepoca.org/taller/issue/view/2>.

Impressas

ALTAMIRANO, Carlos. Peronismo y cultura de izquierda. Buenos Aires, Temas, 2001.

ANZORENA, Oscar. Tiempo de violencia y utopía: del golpe de Onganía (1966) al golpe de Videla (1976). Buenos Aires: Colihue, 1998.

BASCHETTI, Roberto. Documentos 1970-1973: de la guerrilla peronista al gobierno popular (Vol. I). Buenos Aires: De la Campana, 2004.

BONASSO, Miguel. El presidente que no fue: los archivos ocultos del peronismo. Buenos Aires: Planeta 1997.

CANOSA, Mora González. Las Fuerzas Armadas Revolucionarias: orígenes y desarrollo de una particular conjunción entre marxismo, peronismo y lucha armada. 2012, oof. Tesis (Doctorado en Ciencias Sociales ) - Universidad Nacional de La Plata, Facultad de Humanidades y Ciencias de la Educación, La Plata, 2012. 
CANOSA, Mora González. En torno a las Fuerzas Armadas Revolucionarias. Una revisión de la escasa bibliografía sobre el tema y algunas líneas de análisis para su indagación, In: JORNADAS INTERESCUELAS / DEPARTAMENTOSDE HISTORIA, XI, Tucumán, 2007. Anais... Tucumán: Universidad Nacional de Tucumán, 2007.

CAVIASCA, Guillermo. Arturo Lewinger y los orígenes de las FAR, Lucha Armada, Buenos Aires, n.6, p. 82-97, 2006.

CRISTIANISMO Y REVOLUCIÓN. Argentina: Centro de Documentacion de las organizaciones político-militares Argentinas, 1966-1971. Disponible en: <http://eltopoblindado.com/revistacristianismo-y-revolucion/>.

DUHALDE Eduardo L. y PÉREZ, Eduardo. De Taco Ralo a la alternativa independiente: historia documental de las "Fuerzas Armadas Peronistas" y del "Peronismo de Base". Buenos Aires: De la Campana, 2003.

POZZI, Pablo. Por las sendas argentinas.... El PRT-ERP. La guerrilla marxista. Buenos Aires: Imago Mundi [2004].

RODRÍGUEZ OSTRIA, Gustavo. Teoponte: la otra guerrilla guevarista en Bolivia, Lucha Armada en la Argentina, Buenos Aires, n. 2, p.00-00, 2005.

SANTUCHO, Mario Roberto. Escritos [1968-1976]. Rosario: Último recurso, 2006.

TERÁN, Oscar. Lectura en dos tiempos, Lucha armada en la Argentina, Buenos Aires, n. 1, p.oo00, 2004. 